\title{
Nationale Stereotype in literarischem Gewand: Das Bild des Spaniers in den Werken deutschsprachiger protestantischer Autoren während des Dreißigjährigen Krieges
}

\author{
Silvia Serena Tschopp
}

Seinem Schwager, dem Meininger herzoglichen Bibliothekar Wilhelm Friedrich Hermann Reinwald, schreibt Friedrich Schiller in einem Brief vom 27. März 1783, er ,,arbeite nunmehr entschloßen und fest auf einen Dom Karlos zu“. Der Reiz des zu bearbeitenden Stoffs liege, wie der Dichter betont, vor allem darin, dass er ihm „Gelegenheit zu starken Zeichnungen“ biete: „Der Karakter eines feurigen, grosen und empfindenden Jünglings, [...] - einer Königin die durch den Zwang ihrer Empfindung bei allen Vortheilen ihres Schiksals verunglükt, - eines eifersüchtigen Vaters und Gemals - eines grausamen heuchlerischen Inquisitors, und barbarischen Herzogs von Alba und so fort solten mir, dächte ich, nicht wol mislingen." Bemerkenswert an der hier zitierten Briefstelle ist die Charakterisierung des Großinquisitors und des Herzogs von Alba, die einer Tradition geschuldet ist, deren Ursprünge ins 16. Jahrhundert zurückreichen und die in Zusammenhang steht mit den politischen und konfessionellen Verwerfungen, welche der Aufstieg des habsburgischen Spaniens in Europa erzeugte. Wenn allerdings Schiller in seinem 1787 erschienenen Drama den Topos des grausamen Spaniers noch einmal bemüht, ist dies insofern überraschend, als das Spanienbild in Deutschland im Lauf des 18. Jahrhunderts einen signifikanten Wandel erfahren hatte, im Laufe dessen die überwiegend negative Darstellung der iberischen Halbinsel und ihrer Bewohner zunehmend der Imagination Spaniens als eines Sehnsuchtsraums romantischer Phantasie wich. ${ }^{2}$ Dass Schiller die

1 Schillers Werke. Nationalausgabe Bd. 23: Briefwechsel. Schillers Briefe 17721785. Hrsg. von Walter Müller-Seidel, Weimar 1956, S. 74f.

2 Vgl. v. a. Ulrike Hönsch: Wege des Spanienbildes im Deutschland des 18. Jahrhunderts. Von der Schwarzen Legende zum „Hesperischen Zaubergarten“. Tübingen 2000. (=Hermaea. Germanistische Forschungen. Neue Folge 91) Zur Wahrnehmung Spaniens in Deutschland im 18. Jahrhundert vgl. außerdem Christian von Zimmermann: Reiseberichte und Romanzen. Kulturgeschichtliche Studien zur Perzeption und Rezeption Spaniens im deutschen Sprachraum des 18. Jahrhunderts. Tübingen 1997. (=Frühe Neuzeit 38) sowie Zum Spanienbild der Deutschen in der Zeit der Aufklärung. Eine historische Übersicht. Hrsg. von Hans Juretschke. Münster 1997. (=Spanische Forschungen der Görresgesellschaft. Zweite Reihe 33) 
Figuren des Großinquisitors, des Statthalters der Niederlande, aber auch des spanischen Königs als moralisch verwerfliche oder zumindest hochgradig ambivalente Charaktere gestaltet, dürfte nicht zuletzt aus der Tatsache zu erklären sein, dass der Dichter parallel zum Don Carlos an seiner 1788 vollendeten Geschichte des Abfalls der vereinigten Niederlande von der spanischen Regierung arbeitete und sich in diesem Zusammenhang mit der Position der publizistisch äußerst aktiven antispanischen Partei vertraut gemacht hatte. Zugleich belegt Don Carlos die Langlebigkeit stereotyper Vorstellungen des Anderen, hier der Perzeption Spaniens, das während des 16. und 17. Jahrhunderts vor allem in den protestantischen Territorien Europas mit dem Stigma einer in politischer, religiöser und kultureller Hinsicht defizitären Macht behaftet war.

Die vom spanischen Journalisten Julián Juderías mit dem Begriff , leyenda negra " bezeichnete ablehnende Haltung gegenüber dem iberischen Raum soll den Ausgangspunkt meiner Überlegungen zur Genese, Verbreitung und Funktion nationaler Stereotypen und deren Bedeutung innerhalb eines im engeren Sinne als ,literarisch" definierten Zusammenhangs bilden. Den Angelpunkt der folgenden, auf systematischen Anspruch bewusst verzichtenden Erkundungen stellt dabei die Beobachtung dar, dass sich mit Blick auf die frühmoderne publizistisch-literarische Darstellung Spaniens zwar ein dicht übermitteltes Bündel von Stereotypen beschreiben lässt, dass die iberische Halbinsel und deren Bewohner jedoch nicht nur in der zeitgenössischen deutschsprachigen Dichtung keine herausragende Rolle spielen, sondern auBerdem dort, wo sie in Erscheinung treten, nur bedingt mit der im 16. und 17. Jahrhundert vorherrschenden Auffassung ,des' Spaniers in Einklang zu bringen sind. Im Zentrum meiner Ausführungen steht demnach das komplexe, gleichermaßen durch Kongruenz und Differenz gekennzeichnete Verhältnis zwischen der in einer Vielzahl von Quellen dokumentierten, wissenschaftlich, konfessionell und politisch begründeten Auffassung des spanischen Nationalcharakters einerseits und poetischen Imaginationen ,des' Spaniers andererseits. Gefragt wird nach dem Ort der Dichtung innerhalb eines medienübergreifenden Diskurses, den die im engeren Sinne literarische Überlieferung mitkonstituiert, innerhalb dessen sie jedoch zugleich Sonderformen ausbildet und sich damit die Möglichkeit alternativer Deutungsmuster schafft. Dabei konzentriere ich mich vor allem auf die Zeit des Dreißigjährigen Krieges als jenem Moment, in dem die Vorstellung ,des' Spaniers bereits feste Konturen gewonnen hatte und die antispanische Propaganda zugleich ihren letzten Höhepunkt erreichte.

3 Julián Juderias: La leyenda negra. Estudios acerca del concepto de España en el extranjero. Madrid 1914. 
Das hier skizzierte Vorhaben lässt eine Zweiteilung meines Beitrags sinnvoll erscheinen: In einem ersten Schritt soll zunächst knapp auf die Genese der ,leyenda negra' und das damit in Verbindung stehende stereotype Bild ,des' Spaniers seit dem 16. Jahrhundert eingegangen und jene Medien in den Blick gerückt werden, denen für die Vermittlung der in der Frühen Neuzeit vorherrschenden Auffassung ,des' Spaniers primäre Bedeutung zukam, bevor die aktuelle Forschungsdiskussion über Definition, Formen und Funktionen nationaler Stereotypen kurz beleuchtet wird. In einem zweiten Schritt werde ich die Darstellung ,des' Spaniers am Beispiel ausgewählter Werke vor allem Johann Rists rekapitulieren und in ihrem Verhältnis zu zeitgenössischen stereotypen Vorstellungen spanischer Eigenart diskutieren.

\section{I.}

In der umfangreichen Forschung zur ,leyenda negra' besteht inzwischen Konsens darüber, dass die Genese jenes äußerst negativen Bildes ,des' Spaniers, das seit Beginn des 20. Jahrhunderts unter dem Begriff der ,Schwarzen Legende“ subsumiert wird, sich langsamer und komplizierter darstellt, als dies insbesondere die ältere spanische Forschung behauptet hatte. ${ }^{+}$Die Wurzeln der Schwarzen Legende liegen nicht in den durch die Reformation bedingten Konflikten, sondern reichen zurück bis ins Mittelalter; deren europaweite Wirkung verdankt sich außerdem nicht allein den publizistischen Invektiven antispanischer Propagandisten des 16. Jahrhunderts, sondern gründet in drei Ereigniskomplexen, deren interessegeleitete Darstellung aus der

4 Zur ,leyenda negra' wären neben dem Klassiker von Sverker Arnoldsson: La Leyenda Negra. Estudios sobre sus orígenes. Göteborg 1960. (=Acta Universitatis Gothoburgensis Vol. LXVI, 1960, Heft 3) etwa die neueren Studien von Ricardo García Cárcel: La leyenda negra. Historia y opinión. Madrid 1992 oder Jocelyn N. Hillgarth: The Mirror of Spain, 1500-1700. The Formation of a Myth. Ann Arbor 2000, zu nennen. Einen knappen Überblick zur ,Schwarzen Legende' in deutscher Sprache bieten Hönsch, Wege des Spanienbildes (wie Anm. 2), S. 9-29; Wolfgang Reinhard: ,Eine so barbarische und grausame Nation wie diese'. Die Konstruktion der Alterität Spaniens durch die Leyenda Negra und ihr Nutzen für allerhand Identitäten. In: Geschichtsbilder und Gründungsmythen. Hrsg. von Hans-Joachim Gehrke. Würzburg 2001, S. 159-177. (=Identitäten und Alteritäten 7); Holger Kürbis: Hispania descripta. Von der Reise zum Bericht. Deutschsprachige Reiseberichte des 16. und 17. Jahrhunderts über Spanien. Ein Beitrag zur Struktur und Funktion der frühneuzeitlichen Reiseliteratur. Frankfurt a. M. 2004, S. 245-257. (=Europäische Hochschulschriften. Reihe III: Geschichte und ihre Hilfswissenschaften 994) 
Feder sowohl französischer, niederländischer, englischer oder deutschsprachiger als auch iberischer Autoren stammt: Es sind erstens die Berichte über die Gräueltaten der Konquistadoren in Amerika, allen voran Bartolomé de Las Casas Brevísima relación de la destrucción de las Indias (1552), zweitens die kritische Auseinandersetzung mit der spanischen Inquisition, die in zahlreichen Schriften als besonders grausam und fanatisch beschrieben wird, sowie drittens die in die Regierungszeit Philipp II. fallenden militärischen Auseinandersetzungen, insbesondere der Unabhängigkeitskrieg der protestantischen Niederlande gegen die spanisch-habsburgische Herrschaft, welche die Vorstellung Spaniens und der Spanier seit dem 16. Jahrhundert dominieren, eine Vorstellung, die sich als auffallend konstant erweist. Zwar machen die überlieferten Quellen zur Wahrnehmung Spaniens im Europa der Frühen Neuzeit deutlich, dass sich deren Urheber durchaus eigenständig aus einem umfangreichen Fundus an stereotypen Zuschreibungen bedienen konnten, dennoch lassen sich rekurrierende Eigenschaftszuweisungen nennen, die in ihrer Gesamtheit eine tendenziell invariable Auffassung vom Charakter, des' Spaniers begründen: So betont etwa der Verfasser des Lemmas ,Spanien' in Johann Heinrich Zedlers Universal Lexicon aller Wissenschaften und Künste die „Hoffart", die „Faulheit", die „Rachgier" und „Falschheit“, die „Eifersucht", die „Geilheit" oder den fanatischen Katholizismus der Spanier und bietet seinen Lesern damit ein Kondensat all jener Attribute, die den Bewohnern der iberischen Halbinsel in frühneuzeitlichem Schrifttum mit geradezu irritierender Hartnäckigkeit zugeschrieben wurden. ${ }^{5}$

Der vorgängig zitierte Lexikonartikel - ein später Beleg für die sich seit dem 16. Jahrhundert verfestigende Wahrnehmung, des' Spaniers - stellt eine Kompilation dar, die aus all jenen literarischen und publizistischen Gattungen bzw. Medien schöpfen konnte, in welchen im 16. und 17. Jahrhundert Aussagen zum ,Naturell' der Angehörigen europäischer Nationen getroffen wurden. Dies gilt für chronikalisch-ethnographische Schriften, wie etwa Sebastian Münsters Cosmographia universalis (1544), die bereits in den ersten Jahrzehnten nach ihrem Erscheinen weite Verbreitung fand und mit ihrer zwar um Ausgewogenheit bemühten, jedoch insgesamt skeptischen Einschätzung des spanischen Nationalcharakters die Perzeption Spaniens vor allem in gelehrten Kreisen beeinflusst haben dürfte. ${ }^{6}$ Nicht nur die humanistische Geschichtsschreibung, auch die frühbarocke landeskundlich ausgerichtete Historiographie - etwa De Natura Populorum eiusque pro loci positu temporisque decursu variatione (1619) des Tübinger Juristen und Staatswis-

5 Johann Heinrich Zedler: Großes vollständiges Universal Lexicon Aller Wissenschafften und Künste. Bd. 38. Halle und Leipzig 1743, Sp. 1119 .

6 Zur Darstellung Spaniens in Münsters Cosmographia universalis vgl. Hönsch, Wege des Spanienbildes (wie Anm. 2), S. 18ff. 
senschaftlers Christoph Besold - trug zur Vermittlung stereotyper, auf Spanien bezogener Vorstellungen bei, die im akademischen Milieu eine breitere Rezeption erfuhren. Erhebliche Bedeutung kam außerdem der Enzyklopädistik zu. Debora Gerstenberger hat in einer jüngst erschienenen Untersuchung detailliert nachgewiesen, wie eng sich die intertextuellen Bezüge zwischen den frühneuzeitlichen enzyklopädischen Lexika in Europa gestalteten und wie sehr die Darstellung Spaniens und des spanischen Nationalcharakters einem in antiker Überlieferung wurzelnden, durch die immer gleichen Topoi an Überzeugungskraft gewinnenden Beschreibungsmodus verpflichtet war, der kritische Differenzierung kaum zulieb. ${ }^{7}$ Hervorzuheben sind des weiteren Epithetonlexika wie etwa das in zahlreichen Auflagen erschienene Epithetorum opus (1518) des Johannes Ravisius Textor, in dem Autoren das jeweils passende Attribut für die von ihnen zu beschreibenden Phänomene finden konnten, sowie jene moralphilosophischen, nicht selten in das Gewand der Satire gekleideten Werke, in denen der Rekurs auf nationale Stereotype einer vorrangig an die eigenen Landsleute gerichteten Lasterkritik diente, wie dies etwa - um ein besonders berühmtes Beispiel zu nennen - bei Baltasar Graciáns El Criticón (1651-57) der Fall ist. ${ }^{8}$

Gemeinsam ist den bislang erwähnten Schriften, dass sie für eine gelehrte Leserschaft gedacht waren und deshalb vor allem unter Intellektuellen zirkulierten. Zwar ist nicht auszuschließen, dass sie auch außerhalb eines engeren Kreises gelehrter Männer und Frauen Wirkung entfaltet haben; für die Wahrnehmung der iberischen Halbinsel und ihrer Bewohner innerhalb eines breiteren, neben gebildeten, dem Adel und dem gehobenen Bürgertum entstammenden Rezipienten potentiell auch lesefähige Angehörige jener sozialen Schichten, die zeitgenössisch mit der Bezeichnung, gemeiner Mann* angesprochen werden, umfassenden Publikums dürften vor allem die Reiseliteratur und, in noch höherem Maße, die politische Publizistik von Bedeutung gewesen sein.' Dank Holger Kürbis' kürzlich veröffentlichter Studie

7 Vgl. Debora Gerstenberger: Iberien im Spiegel frühneuzeitlicher enzyklopädischer Lexika Europas. Diskursgeschichtliche Untersuchung spanischer und portugiesischer Nationalstereotypen des 17. und 18. Jahrhunderts. Stuttgart 2007. (=Beiträge zur Wirtschafts- und Sozialgeschichte 110)

8 Zur Bedeutung nationaler Stereotypen in Baltasar Graciáns El Criticón vgl. Ulrich Schulz-Buschhaus: Der Völkervergleich in der Allegorie - Graciáns $E l$ Criticón und Boccalinis I Ragguagli di Parnaso. In: Europäischer Völkerspiegel. Imagologisch-ethnographische Studien zu den Völkertafeln des frühen 18. Jahrhunderts. Hrsg. von Franz K. Stanzel. Unter Mitwirkung von Ingomar Weiler und Waldemar Zacharasiewicz. Heidelberg 1999, S. 139-153.

9 Für die Vermittlung der Vorstellung , des' Spaniers haben Bildquellen eine Rolle gespielt, deren systematische Erforschung noch aussteht. Die Darstellung ,des* 
über deutschsprachige Reiseberichte des 16. und 17. Jahrhunderts über Spanien sind wir inzwischen gut unterrichtet über das AusmaB und die spezifische Form jener Beschreibungen Spaniens, die frühneuzeitliche Reisende hinterlassen haben. ${ }^{10}$ So unterschiedlich die Motive der Spanienreisenden auch waren - nach Spanien reisten Gläubige, die Santiago de Compostela, einen der wichtigsten Wallfahrtsorte Europas, zu ihrem Ziel erkoren hatten, meist adlige junge Männer, welche der iberischen Halbinsel im Rahmen ihrer Kavalierstour einen Besuch abstatteten, Diplomaten, die sich im Auftrag europäischer Fürsten vorübergehend am Hof des spanischen Königs aufhielten, Kaufleute, die in Handelsgeschäften unterwegs waren oder Söldner, die in spanischen Diensten kämpften -, so vielgestaltig die sich frïhmodernen Spanienreisenden zu verdankende schriftliche Überlieferung auch erscheinen mag - neben Itineraren finden sich handschriftliche Tagebücher und Briefe sowie meist gedruckte Reiseführer und Reiseberichte -, so sehr konvergieren die verschiedenen Quellen in ihrer Darstellung spanischer Eigenart. Im Rahmen ihrer kompilierend verfahrenden Beschreibung Spaniens bemühen sich die Autoren nicht darum, überlieferte Topoi zu überprüfen und, falls notwendig, zu revidieren; sie bestätigen vielmehr verbreitete und offenbar als autoritativ empfundene stereotype Setzungen." Dass die Spanier eher zum Waffenhandwerk geeignet als zum Ackerbau geneigt seien, dass ihr Stolz und ihr Hang zu einer adeligen Lebensweise sie zwinge, für die Ökonomie des Landes zentrale Bereiche wie Landwirtschaft, Handwerk und Handel Ausländern zu überlassen oder dass die mächtige spanische Inquisition ihre Ziele mit besonderer Grausamkeit verfolge, wie eine Mehrheit der überlieferten Quellen behauptet, erklärt sich weniger aus der persönlichen Erfahrung der Reisenden als vielmehr aus deren Kenntnis der zeitgenössischen geographisch-statistischen Literatur. Die frühneuzeitlichen Reiseberichte tragen demnach nicht etwa zu einer realistischeren Wahrnehmung Spaniens bei, sie zementieren im Gegenteil jene literarisch konstruierte Vorstellung ,des' Spaniers, deren Ubiquität den Ausgangspunkt meiner Überlegungen bildete.

Wie die Forschung früh bemerkt hat, sind es jedoch in erster Linie die zahlreich gedruckten politischen Flugschriften und Flugblätter, die seit der Mitte des 16. Jahrhunderts und bis zum Westfälischen Frieden die Perzeption Spaniens maßgeblich beeinflusst haben. ${ }^{12}$ Nachdem der Schmalkaldische

Spaniers in Gemälden und vor allem in der Druckgraphik soll auch hier ausgeklammert bleiben.

10 Kürbis, Hispania descripta (wie Anm. 4).

11 Vgl. ebenda, S. 198-244.

12 Zur antispanischen Publizistik vgl. v. a. Peer Schmidt: Spanische Universalmonarchie oder ,teutsche Libertet“. Das spanische Imperium in der Propaganda des 
Krieg zu einer ersten Welle antispanischer Publizistik geführt hatte und zu Beginn der 1560er Jahre sowohl in England als auch in Frankreich zumeist protestantische Autoren eine Kampagne gegen den spanischen Monarchen entfachten, ist es vor allem der Unabhängigkeitskrieg der Niederlande, der eine große Zahl von Pamphleten und Einblattdrucken hervorbrachte, die in nicht selten äußerst polemischer Form den spanischen Hegemonialanspruch denunzierten und in diesem Zusammenhang jene stereotypen Vorstellungen spanischer Eigenart aktualisierten und zugleich zuspitzten, die seit dem humanistischen Diskurs über die Merkmale europäischer , nationes ' durch die gelehrte Literatur geisterten ${ }^{13}$ und die in einem im letzten Viertel des 16. Jahrhundert gedruckten, sowohl in deutscher als auch in französischer Sprache überlieferten Flugblatt, welches in polemischer Absicht das „Leben/ die Thaten/ Sitten [...] deß Signor Spangniols“" darstellt, gebündelt erscheinen. ${ }^{1+}$

Dreißigjährigen Krieges. Stuttgart 2001. (=Studien zur modernen Geschichte 54) An weiteren Beiträgen sollen außerdem genannt werden: Judith Pollmann: Eine natürliche Feindschaft: Ursprung und Funktion der schwarzen Legende über Spanien in den Niederlanden, 1560-1581. In: Feindbilder. Die Darstellung des Gegners in der politischen Publizistik des Mittelalters und der Neuzeit. Hrsg. von Franz Bosbach. Köln, Weimar und Wien 1992, S. 73-93. (=Bayreuther Historische Kolloquien 6); Dietrich Briesemeister: „allerhand iniurien schmehkarten pasquill vnd andere schandlose ehrenrürige Schriften vnd Model“". Die antispanischen Flugschriften in Deutschland zwischen 1580 und 1635. In: Wolfenbütteler Beiträge 4 (1981), S. 147-190 sowie die Fallstudie von Gerhart Hoffmeister: Das spanische Post- und Wächterhömlein. Zur Verbreitung der Leyenda Negra in Deutschland (1583-1619). In: Archiv für Kulturgeschichte 56 (1974), S. 350-371.

13 Zur Bedeutung des Humanismus für die Vermittlung nationaler Stereotype vgl. z. B. Winfried Schulze: Die Entstehung des nationalen Vorurteils. Zur Kultur der Wahmehmung fremder Nationen in der europäischen Frühen Neuzeit. In: Menschen und Grenzen in der Frühen Neuzeit. Hrsg. von Wolfgang Schmale und Reinhard Stauber. Berlin 1998, S. 23-49. (=Innovationen. Bibliothek zur Neueren und Neuesten Geschichte 2) Vgl. auch Michael Maurer: ..Nationalcharakter" in der frühen Neuzeit. Ein mentalitätsgeschichtlicher Versuch. In: Transformationen des Wir-Gefühls. Studien zum nationalen Habitus. Hrsg. von Reinhard Blomert. Helmut Kuzmics und Annette Treibel. Frankfurt a. M. 1993. S. $45-81$.

14 Das Flugblatt ist abgedruckt in Deutsche illustrierte Flugblätter des 16. und 17. Jahrhunderts. Hrsg. von Wolfgang Harms. Band II: Die Sammlung der Herzog August Bibliothek in Wolfenbuittel: Historica. Kommentierte Ausgabe. Hrsg. von Wolfgang Harms zusammen mit Michael Schilling und Andreas Wang. Tübingen 1997, Nr. 37 (französische Fassung) und Nr. 38 (deutsche Fassung). Zum Flugblatt über den „Signor Spangniol“ vgl. Dietrich Briesemeister: Der sultrische Bilderbogen vom „Signor Spangniol“. In: Traza y Baza. Cuadernos Hispanos de Simbología 9 (1985), S. 5-20. 
Einen weiteren und letzten Kulminationspunkt antispanischer Publizistik bildet schließlich jenes über 270 Flugschriften und eine große Zahl von Einblattdrucken umfassende Korpus publizistischer Veröffentlichungen, die zwischen 1618 und 1648 die politische und militärische Rolle Spaniens im DreiBigjährigen Krieg reflektieren. ${ }^{\text {.s }}$

Es sind vor allem die nicht nur in den protestantischen Territorien Europas verbreiteten politischen Invektiven gegen den spanischen ,Imperialismus', welche in der ersten Hälfte des 17. Jahrhunderts auch und gerade auf dem Gebiet des Heiligen Römischen Reichs deutscher Nation jene Auffassung ,des`Spaniers popularisiert haben dürften, die ich eingangs im Rückgriff auf den Zedlerschen Lexikonartikel zu Spanien angedeutet hatte. Wer sich im hier interessierenden Zeitraum mit Spanien und ,dem' Spanier befasst, hat zunächst ein Bild vor Augen, das sich aus einigen wenigen, literarisch legitimierten Versatzstïcken zusammensetzt, die mit Begriffen wie ,stolz', ,hochmütig', ,ehrgeizig', ,grausam', ,gewalttätig', ,kriegerisch', ,hinterhältig', ,fanatisch', ,enthaltsam', , habgierig', , wollüstig ' und ,fromm' korreliert sind. ${ }^{16}$ Ungeachtet der zweifellos nicht nur erfreulichen Erfahrungen, welche die militärischen und religiösen Kontrahenten Philipps II. mit der spanischen Monarchie gemacht hatten, wird deutlich, dass die keinesfalls widerspruchsfreie Vorstellung ,des' Spaniers, die den Diskurs um europäische Nationalcharaktere im frühneuzeitlichen Europa dominiert, nicht allein und nicht einmal primär in historischer Wirklichkeit gründet, sondern ein in spezifischen literarischen Traditionen fußendes Konstrukt darstellt. Mag dieses seine Plausibilität wesentlich aus tatsächlicher oder auch nur scheinbarer Übereinstimmung mit lebensweltlicher Erfahrung gewinnen, besteht sein besonderer Nutzen dennoch gerade darin, dass es nicht ein reale Verhältnisse abbildendes, sondern ein durch gelehrte Überlieferung autorisiertes, festgefügtes und zugleich variabel dem jeweiligen Interesse desjenigen, der sich seiner bedient, sich anpassendes Instrument wissenschaftlicher, politischer, konfessioneller und ästhetischer Kommunikation darstellt. Es weist demnach die zentralen Merkmale jenes Phänomens auf, das, durch den amerikanischen Publizisten Walter Lippmann (Public Opinion, New York 1922) unter den Begriff des ,Stereotyps" gefasst und in die Diskussion eingeführt, seit dem frühen 20. Jahrhundert einen zunehmend intensiv erforschten Gegenstand sozialpsychologischer und medienwissenschaftlicher Analyse bildet. ${ }^{17}$

15 Vgl. dazu die Monographie von Schmidt, Spanische Universalmonarchie (wie Anm. 12).

16 Eine prägnante Zusammenfassung des in der Frühen Neuzeit verbreiteten ,Identikit' des Spaniers findet sich in Gerstenberger, Iberien (wie Anm. 7), S. 152.

17 Der Begriff des ,Stereotyps“ ist zunächst vor allem im Rahmen sozialwissenschafticher bzw. sozialpsychologischer Fragestellungen aufgegriffen und ge- 
,Stereotyp' wird definiert als eine kollektiv geteilte, vereinfachende, generalisierende, änderungsresistente und in der Regel emotional aufgeladene Vorstellung über sich selbst (Autostereotyp) oder über andere (Heterostereotyp), die den Anspruch erhebt, wahr zu sein. Konsens besteht zum gegenwärtigen Zeitpunkt darüber, dass es sich bei Stereotypen nicht um erfahrungsgesättigte Beschreibungen von Wirklichkeit handelt, sondern um diskursiv erzeugte Konstruktionen, die nur adäquat verstanden werden können, wenn die sozialen und kulturellen Bedingungen ihrer Genese und ihres Gebrauchs Berücksichtigung finden. Die im analytischen Umgang mit Stereotypen zu beantwortende Frage lautet deshalb nicht, ob eine stereotype Eigenschaftszuweisung richtig oder falsch ist, sondern weshalb in einem spezifischen Moment in einem spezifischen kulturellen Kontext ein spezifisches Stereotyp verwendet wird. ${ }^{18}$ Im Zentrum der Beschäftigung mit Stereotypen steht demnach deren jeweilige Funktion und so ist es kein Zufall, dass neuere Untersuchungen, die sich mit Stereotypen befassen, ihren Fokus auf die Leistung stereotyper Merkmalszuschreibungen richten. Die diesen Forschungsbemühungen zu verdankenden Erkenntnisse erweisen sich gerade mit Blick auf die besonders

schärft worden (vgl. dazu den Überblick in Jochen Konrad: Stereotype in Dynamik. Zur kulturwissenschaftlichen Verortung eines theoretischen Konzepts. Tönning, Lübeck und Marburg 2006, S. 5-75). Erst in jüngerer Zeit hat der Begriff auch innerhalb der Geisteswissenschaften größere Relevanz erlangt. Neben linguistischen [vgl. etwa Magda Telus: Gruppenspezifisches Stereotyp: Ein textlinguistisches Modell. In: Stereotyp, Identität und Geschichte. Die Funktion von Stereotypen in gesellschaftlichen Diskursen. Hrsg. von Hans Henning Hahn. Frankfurt a. M. 2002, S. 87-124. (=Mitteleuropa-Osteuropa. Oldenburger Beiträge zur Kultur und Geschichte Ostmitteleuropas 5)] sind es vor allem ethnologische [Heike Müns: Arbeitsfelder und Methoden volkskundlicher Stereotypenforschung. In: Hahn (Hg.), Stereotyp, Identität und Geschichte (wie Anm. 17), S. 125-154] und historische [Hans Henning Hahn: Stereotypen in der Geschichte und Geschichte im Stereotyp. In: Historische Stereotypenforschung. Methodische Überlegungen und empirische Befunde. Hrsg. von Hans Henning Hahn. Oldenburg 1995, S. 190-204. (=Oldenburger Schriften zur Geschichtswissenschaft 2) sowie vor allem Hans Henning Hahn und Eva Hahn: Nationale Stereotypen. Plädoyer für eine historische Stereotypenforschung. In: Hahn (Hg.). Stereotyp, Identitäl und Geschichte (wie Anm. 17), S. 17-56] Beiträge. die neue Perspektiven in der Erforschung von Stereotypen aufgezeigt haben. Eine aktuelle Darstellung zentraler Positionen bietet Ruth Florack: Bekannte Fremde. Zu Herkunft und Funktion nationaler Stereotype in der Literatur. Tübingen 2007. S. 33-58. (=Studien und Texte zur Sozialgeschichte der Literatur 114)

$18 \mathrm{Vgl}$. dazu etwa Michael Imhof: Stereotypen und Diskursanalyse. Anregungen zu einem Forschungskonzept kulturwissenschafticher Stereotypenforschung. In: Hahn (Hg.), Stereotyp, Identität und Geschichte (wie Anm. 17), S. 57-71, hier S. 64f. 
intensiv diskutierten nationalen Stereotype als besonders erhellend. Stereotype, dies zusammenfassend der Befund, dienen dern Abbau von Komplexität und tragen so zu einer Ökonomisierung der Kommunikation bei, sie wirken kohäsionsbildend und systemstabilisierend, indem sie durch die Konstruktion von Alterität, durch die Bezugnahme auf als ,fremdartig' definierte Kollektive zugleich ein Identitätsangebot für die eigene, vertraute Gemeinschaft generieren, sie schaffen Ordnung und erleichtern die Orientierung in einer als unübersichtlich wahrgenommenen Welt, da sie verwirrende Sachverhalte durch Vereinfachung überschau- und handhabbar erscheinen lassen, sie legitimieren und motivieren Handeln dadurch, dass sie einen differenzierten Blick auf andere, seien dies Minderheiten oder Angehörige einer anderen Nation, verstellen und die Hemmschwelle, gegen dieses Andere offensiv vorzugehen, senken.

In welch hohem Maße Stereotype die vorgängig genannten Funktionen zu entfalten vermögen, veranschaulicht besonders prägnant die antispanische Publizistik, die während eines Zeitraums von etwa hundert Jahren die Perzeption der Spanier in Europa maßgeblich prägte. In frühneuzeitlichen Flugschriften und Flugblättern steht ,der' Spanier für ein Bündel an konventionalisierten Eigenschaftszuweisungen; keiner weiteren Erörterung bedürfend fungiert er als ,Schlagwort', mit dem die konfessionelle Identität und der politische Zusammenhalt der von ihm unterdrückten Protestanten beschworen, die historischen Erfahrungen von Niederlage und Sieg geschichtstheologisch verortet und zugleich zum Kampf gegen den religiösen und politischen Gegner aufgenufen werden kann. ${ }^{19}$ Dass ein zunächst in gelehrter Literatur etabliertes negatives nationales Stereotyp im Meinungskampf Anwendung findet, um politische Kontrahenten zu denunzieren, wird ebenso wenig überraschen wie die Tatsache, dass innerhalb der einschlägigen Publizistik die stereotype Vorstellung, des'Spaniers nicht nur keine Relativierung erfährt, sondern im Gegenteil zusätzlich zementiert wird. Wie steht es jedoch um die Dichtung, inwiefern lässt sich die in einer Vielzahl frühneuzeitlicher Quellen bezeugte Auffassung eines spanischen ,Nationalcharakters' auch in der Art und Weise, wie Repräsentanten Spaniens in lyrischen, dramatischen oder epischen Manifestationen in Erscheinung treten, belegen? Oder anders gefragt: Partizipiert die poetische Literatur an der Konstruktion und Popularisierung auf die iberische Halbinsel und ihre Bewohner bezogener nationaler Stereotype oder bildet sie ein System, das im Umgang mit dem überlieferten Fundus an Stereotypen und insbesondere nationalen Stereotypen eigenen

19 Auf die spezifischen politisch-konfessionellen Funktionen der antispanischen Publizistik gehen Schmidt, Spanische Universalmonarchie (wie Anm. 12), S. 95333 und Pollmann, Eine natürliche Feindschaft (wie Anm. 12) ausfiuhrlich ein. 
Regeln folgt? Es sind diese Fragen, die im Zentrum der folgenden Erörterungen stehen sollen.

\section{II.}

Von der vor allem an sozialpsychologischen, ethnologischen und historischen Problemstellungen entzündeten Diskussion um Begriff und Funktion des ,nationalen Stereotyps' ist die Literaturwissenschaft nicht unberührt geblieben. Es ist vor allem die ,komparatistische Imagologie', die sich um eine systematische und methodisch fundierte Analyse kultureller Stereotypen in literarischen Texten bemüht hat. Komparatistische Imagologie meint hier einen zunächst in Frankreich postulierten ${ }^{20}$ und in der Folge auch in Deutschland aufgegriffenen und weiterentwickelten Forschungsansatz, der sich mit der „Untersuchung nationenbezogener Auto- und Hetero-Images in der Literatur selbst sowie in allen Bereichen der Literaturwissenschaft und -kritik" sowie mit der ,Erklärung von Genese und Wirkung dieser Images im literarischen und $[\ldots]$ im extraliterarischen Bereich" beschäftigt. ${ }^{2 !}$ Die komparati-

20 Zur historischen Genese der komparatistischen Imagologie vgl. Manfred S. Fischer: Nationale Images als Gegenstand Vergleichender Literaturgeschichte. Untersuchungen zur Entstehung der komparatistischen Imagologie. Bonn 1981. (=Aachener Beiträge zur Komparatistik 6)

21 Manfred S. Fischer: Literarische Imagologie am Scheideweg. Die Erforschung des „Bildes vom anderen Land“ in der Literatur-Komparatistik. In: Erstartes Denken. Studien zu Klischee, Stereotyp und Vorurteil in englischsprachiger Literatur. Hrsg. von Günther Blaicher. Tübingen 1987, S. 55-71, hier S. 56. Fischer hat sein Konzept komparatistischer Imagologie in einer Reihe teils älterer Beiträge dargelegt [Literarische Seinsweise und politische Funktion nationenbezogener Images. Ein Beitrag zur Theorie der komparatistischen Imagologie. In: Neohelicon 10 (1983), S. 251-274; Komparatistische Imagologie. Für eine interdisziplinäre Erforschung national-imagotyper Systeme. In: Zeitschrift für Sozialpsychologie 10 (1979), S. 30-44]. Zur komparatistischen Imagologie vgl. auch die diesbezüglichen Überlegungen von Hugo Dyserinck [Komparatistische Imagologie. Zur politischen Tragweite einer europäischen Wissenschaft von der Literatur. In: Europa und das nationale Selbstverständnis. Imagologische Probleme in Literatur, Kunst und Kultur des 19. und 20. Jahrhunderts. Hrsg. von Hugo Dyserinck und Karl Ulrich Syndram. Bonn 1988, S. 13-33. (=Aachener Beiträge zur Komparatistik 8); Komparatistische Imagologie jenseits von „Werkimmanenz“ und „Werktranszendenz“. In: Synthesis 9 (1982). S. 27-40: Zum Problem der ,images" und ,mirages" und ihrer Untersuchung im Rahmen der Vergleichenden Literaturwissenschaft. In: Arcadia 1 (1966), S. 107-120]. Eine gleichermaßen prägnante und aktuelle Auseinandersetzung mit der komparatisti- 
stische Imagologie, die sich als konstitutiver Bestandteil der Vergleichenden Literaturwissenschaft verstanden wissen will, geht von der Überzeugung aus, dass die sich in dichterischen Artefakten manifestierenden Figurationen fremdkultureller Erfahrung nicht losgelöst von den jeweils im außerliterarischen Kontext vorherrschenden Konzeptionalisierungen nationaler Alterität gelesen werden können. Zwar interessieren nationale ,Images' in erster Linie insofern ihnen für das Verständnis poetischer Werke Signifikanz zukommt, zugleich jedoch plädieren die Begründer und Verfechter der komparatistischen Imagologie für eine Auffassung von Literatur, die diese nicht in einem autonomen Raum fernab historischer Lebenswelten ansiedelt, sondern im Bewusstsein der gesellschaftspolitischen Dimension literarischer Kommunikation das komplexe Gefüge zwischen literarischen und außerliterarischen Wahrnehmungen des Eigenen und Fremden in den Blick nimmt.

Für den von der komparatistischen Imagologie postulierten engen $\mathrm{Zu}$ sammenhang zwischen literarischer und außerliterarischer Imagination nationaler Eigenart spricht die Tatsache, dass bereits frühneuzeitliche Poetiken unter Berufung auf die aristotelische Dichtungslehre den Autoren empfahlen, sich bei der Gestaltung ihrer Charaktere an gängigen Vorstellungen hinsichtlich des Naturells europäischer Völker zu orientieren. ${ }^{22}$ So hebt Scaliger in seinen Poetices libri septem (1561) hervor, wenn Dichtung dem Prinzip der verisimilitudo zu folgen habe, sei es für den Autor notwendig, bei der Gestaltung seiner Figuren sowohl standes-, geschlechts- oder altersspezifische Spezifika als auch die sich aus der Volks- oder Stammeszugehörigkeit ergebenden Prämissen zu berücksichtigen, und spricht sich in diesem Zusammenhang dafür aus, sich an Geschichtswerken, Sprichwörtern und dem Volksmund zu orientieren. ${ }^{23}$ Mit Blick auf die Spanier hält er in unverkennbarer Anlehnung an seit der Antike überlieferten Darstellungsmustem fest:

Die Spanier führen ein karges Leben zuhause und sind an fremden Tischen großzügig; sie sind munter, trunksüchtig, geschwätzig und prahlerisch; sie haben ein fürchterlich abweisendes Benehmen, einen höllischen Stolz und sind entsetzlich geizig; in der Armut sind sie mutig; die Zuverlässigkeit ihres Wortes bemißt sich

schen Imagologie findet sich in Florack: Bekannte Fremde (wie Anm. 17), S. 732.

22 Vgl. Franz K. Stanzel: Der literarische Aspekt unserer Vorstellungen vom Charakter fremder Völker. In: Anzeiger der Österreichischen Akademie der Wissenschaften. Philosophisch-Historische Klasse 111 (1974), S. 63-82.

23 Vgl. Iulius Caesar Scaliger: Poetices libri septem/Sieben Bücher über die Dichtkunst. Bd. II: Buch 3, Kapitel 1-94. Hrsg., übersetzt, eingeleitet und erläutert von Luc Deitz. Stuttgart-Bad Cannstatt 1994, S. 229. Die entsprechende Stelle lautet: „Gentium itaque ac populorum ingenia tum ex historiis, tum ex proverbiis atque ex ore vulgi excipienda censeo." 
nach dem Preis; sie beneiden alle Völker und werden von allen beneidet. Nur ein Volk überragt sie an seelischer Verworfenheit, ist ihnen aber an Größe unterlegen: die Ligurer. ${ }^{24}$

Ähnlich argumentiert fast achtzig Jahre später der französische Dramatiker und Theaterkritiker Hippolyte-Jules Pilet de la Mesnardière. In seiner 1640 erschienenen Poétique fordert er eine Gestaltung der dramatischen Charaktere, die, dem Gesetz der ,vraisemblance‘ folgend, ihrem Alter, ihrer Affektlage, ihrem Schicksal, ihren Lebensbedingungen, ihrer Nationalität und ihrem Geschlecht angemessen ist. ${ }^{25}$ In seiner Beschreibung der Bewohner der iberischen Halbinsel liefert de la Mesnardière dann so gut wie alle zeitgenössisch verbreiteten Vorurteile über Spanien: „Les Espagnols [seront] présomptueux, inciuils aux étrangers, sçauans dans la Politique, tyrans, auares, constans, capables de toutes fatigues, indifferens à tous climats, ambitieux, méprisans, graues iusqu' à l'extrauagance, passionnez aueuglément pour la gloire de leur Nation, ridicules dans leurs amours, \& furieux dans leur haine. “26

Pilet de la Mesnardières Charakterisierung ,des* Spaniers ist insofern bemerkenswert, als sie, wie diejenige Scaligers, zwar auf bereits in der Antike kolportierte Vorstellungen hinsichtlich der Eigenart der Iberer rekurrien, jedoch zugleich - indem sie etwa auf die tyrannische Art und den Nationalstolz der Spanier hinweist - in der zeitgenössischen antispanischen Polemik verbreitete Stereotype inkorporiert. Sie dokumentiert damit jene literarisch tradierte und legitimierte kollektive europäische Phantasmagorie, die, so steht zu erwarten, auch für die während des Dreißigjährigen Krieges schriftstellerisch tätigen deutschsprachigen Autoren leitend gewesen sein dürte, wenn es darum ging, die Bewohner der iberischen Halbinsel in dichterischer Form zu thematisieren. Zumindest den Protestanten unter ihnen müsste allein schon aus politischen und konfessionellen Erwägungen daran gelegen gewesen sein, ein tendenziell negatives Bild Spaniens und der Spanier zu zeichnen, waren einige durch die spanischen Kriegszüge in den 1620er Jahren doch direkt betroffen. So überrascht es denn auch kaum, wenn der mit dem Heidelberger kurpfälzischen Hof Friederichs V. eng verbundene Julius Wilhelm Zincgref in einigen seinem Fürsten anlässlich dessen Wahl zum böhmischen König gewidmeten Versen und vor allem in Flugblättern und

24 Ebenda, S. 231. Die Stelle lautet im lateinischen Original: „Hispanis vicrus asper domi; alienis mensis largi. alacres, bibaces, loquaces, iactabundi; fastus Tartareus, supercilium Cerbereum, avaritia immanis, paupertate fortes, fidei firmitas ex pretio, omnibus nationibus et invidentes et invisi. Una natio illos superat animi pravitate, magnitudine vincitur: Ligures."

25 Hippolyte-Jules Pilet de la Mesnardière: La Poëtique. Paris 1640 [Reprint: Genf 1972], S. 119.

26 Ebenda, S. 122f. 
Flugschriften, allen voran in seinem Quodlibetischen Welt vnd Hummel Kefig (1632), Spanien scharf attackiert. ${ }^{27}$ Der 1622 nach dem Einfall kaiserlicher Truppen in die Pfalz unter Zurücklassung seines Besitzes aus seiner Heimatstadt Heidelberg geflohene Zincgref ist nicht der einzige, der die Wirren des Dreißigjährigen Krieges am eigenen Leib erlebt hat und sie zum Gegenstand seiner Dichtung macht. Auch Martin Opitz, der 1619 an der Heidelberger Universität ein Studium aufgenommen hatte und den Mitgliedern jenes späthumanistischen Kreises von Dichtern und Gelehrten, zu dem unter anderen Zincgref gehörte, noch nach seinem Wegzug aus Heidelberg verbunden blieb, nahm regen Anteil an den für die Pfalz verheerenden Ereignissen der frühen 1620er Jahre. In einem Gedicht mit dem sprechenden Titel Ein Gebet, daß Gott die Spanier widerumb vom Rheinstrom wolle treiben (1620) ruft er den Höchsten, den „grosse[n] Capitain“ auf, den „Scheußlichen Maranen" Einhalt zu gebieten, ${ }^{28}$ und in seinen 1621 entstandenen Trostgetichte in Widerwertigkeit des Krieges spart er nicht mit Kritik an den als tyrannisch und grausam dargestellten Spaniern. ${ }^{29}$ Eine wohl im Auftrag des protestantischen Heerführers Ernst Graf von Mansfeld verfasste Ode des im englischen Staatsdienst tätigen deutschen Lyrikers Georg Rodolf Weckherlin mit dem Titel Die fünfte Ode, oder Lied, Gemacht auff eines Fürstens begehren (1624) zeugt ebenfalls von der Bereitschaft protestantischer Autoren, ihr dichterisches Schaffen in den Dienst der Politik zu stellen: In einem als verbaler Schlagabtausch zwischen Spaniern und Deutschen inszenierten Dialog entgegnen Letztere dem Hochmut und Reichtum Spaniens mit dem Hinweis auf die militärische Stärke der Mansfeldischen Truppen und auch in Ode. Wie die Soldaten man [...] Ermahnet [...] zu streitten (1641) desselben Verfassers sollen die „Tyrannen wuht" und die „titul/ torheit und stoltzieren“ der spanischen Soldaten durch deutsche Kämpfer überwunden werden. ${ }^{30}$

27 Zu Julius Wilhelm Zincgref vgl. Axel E. Walter: Ein politischer Publizist im Dreißigjährigen Krieg: Das literarische Schaffen Julius Wilhelm Zincgrefs. In: 1648. Krieg und Frieden in Europa. Hrsg. von Klaus Bußmann und Heinz Schilling. Bd. II: Kunst und Kultur. [Münster] 1998, S. 377-383.

28 Das Gedicht ist abgedruckt in Martin Opitz: Teutsche Poemata. Abdruck der Ausgabe von 1624 mit den Varianten der Einzeldrucke und der späteren Ausgaben. Hrsg. von Georg Witkowski. Halle 1902, S. $148 f$.

29 Vgl. dazu Christoph Eugen Schweitzer: Spanien in der deutschen Literatur des 17. Jahrhunderts. Diss. [masch.] Yale 1954 [Mikrofilm: Ann Arbor 1967], S. $32 \mathrm{ff}$.

30 Das erstgenannte Gedicht findet sich in Georg Rudolf Weckherlins Gedichte. Hrsg. von Hermann Fischer. Bd. 2. Hildesheim 1968, S. $219 \mathrm{ff}$. Der vollständige Titel des zweiten Gedichts lautet: Wie die Soldaten man vorzeiten Laut mit dem mund: So Sie ietzund Ermahnet der Poêt zu streitten. Es ist abgedruckt in Georg 
Wenn man bedenkt, dass sich während des Dreißigjährigen Krieges bedeutende Dichter am politischen Meinungskampf beteiligten, ${ }^{31}$ wenn man außerdem berücksichtigt, dass die während der sich über Jahrzehnte hinziehenden militärischen Auseinandersetzungen veröffentlichten Flugblätter und Flugschriften auf äußerst einprägsame Weise die durch die ,Schwarze Legende' popularisierten Vorstellungen , des'Spaniers instrumentalisierten, um ihrer politischen Botschaft größere Wirkung zu verleihen, mag es verwundern, dass die Zahl poetischer Belege für den Topos des stolzen und grausamen Spaniers in der deutschsprachigen Dichtung der Zeit insgesamt gering ist. ${ }^{32}$ Die vorgängig Genannten gehören zu den wenigen Autoren, die das zeitgenössisch propagierte Feindbild des Spaniers in politischer Absicht aufgreifen; sie tun dies außerdem vor allem zu Beginn der kriegerischen Auseinandersetzungen. In den späteren Phasen des Dreißigjährigen Kriegs spielen Spanien und Spanier auch in der fiktionalen Literatur protestantischer Provenienz eine untergeordnete Rolle und dies durchaus im Gegensatz zur Publizistik, in der die antispanische Polemik im Zuge der schwedischen Kriegsführung auf Reichsgebiet eine Intensivierung erfährt. Insofern stellt Johann Rist, der im Folgenden etwas ausführlicher diskutiert werden soll, eine Ausnahme dar, enthält sein Werk doch gleich mehrere Passagen, in denen Spanier und einige der mit diesen korrelierten Stereotypen begegnen.

Der früheste Beleg für den Topos des stolzen Spaniers findet sich bei Rist im zweiten Akt seiner 1630 erschienenen, gemeinsam mit Ernst Stapel verfassten Irenaromachia. Im dort inszenierten Wechselgespräch zwischen einem englischen, einem spanischen und einem deutschen Soldaten geht es zwar um die von allen Figuren geteilte Aversion gegen ,den' Franzosen, wenn sich allerdings der ,Hispanus" in einer sprachlich verqueren Invektive gegen „das Frantzoß" der eigenen „Nobleza“, die ,viel groß“ sei „als sin dusent Fürst“", und seines ,,adlick[en] Aug[es] "rühmt, legt er jenen Hochmut und Adelsstolz an den Tag, der den Spaniern im frühneuzeitlichen Schrift-

Rudolf Weckherlins Gedichte (wie Anm. 30). Bd. 1, S. 496ff. Vgl. auch Der Sp: Soldaten Grabschrifft im selben Band, S. 455.

31 Zur politischen Dichtung während des Dreißigjährigen Krieges vgl. den knappen Überblick von Wilhelm Kühlmann: Krieg und Frieden in der Literatur des 17. Jahrhunderts. In: Bußmann/Schilling (Hg.), 1648. Krieg und Frieden in Europa (wie Anm. 27), S. 329-337.

32 Schon Georg Herbert Walz: Spanien und der spanische Mensch in der deutschen Literatur vom Barock zur Romantik. Erlangen 1966 war aufgefallen, dass in deutschsprachigen Dramen des Barock nur selten spanische Figuren begegnen und dies auch nur dann, wenn der jeweils behandelte Stoff es vorschreibt, wie etwa im Fall von Andreas Gryphius' Cardenio und Celinde [vgl. Walz, Spanien und der spanische Mensch, (wie Anm. 32), S. 13]. 
tum immer wieder vorgeworfen wurde. ${ }^{33}$ Auch in Rists weit berühmterem Drama Das Friedewünschende Teutschland (1647) tritt im zweiten Akt ein Repräsentant der iberischen Halbinsel auf: Wie die anderen europäischen Kavaliere, die sich der Personifikation Germaniens als Verehrer andienen, hofft auch der spanische Edelmann Don Antonio für seine Schmeicheleien reich belohnt zu werden; anders als bei seinen Rivalen zielt sein Werben jedoch weder auf ein wertvolles Pferd noch auf Kleinodien oder Geld, sondern auf ,ansehnliche[n] Amteren und hohe[n] Ehren“. ${ }^{34}$ Zur Überheblichkeit und zum Ehrgeiz des spanischen Kavaliers passt dessen Vorliebe für „Höffligkeit“" und „Ceremonien“. ${ }^{35}$ Wenn er Teutschland mit den Worten anspricht „Allergnädigste Königinn/ es wiederfähret uns die allerhöheste Ehre der Welt/ in deme wir gewürdiget werden $E<$ uer> Majestät die Hände zu küssen/ ja so gahr an deroselben Königlichen Taffel tractiret zu werden, ${ }^{\text {‘a }}$ legt er genau jenes dem spanischen Hofzeremoniell geschuldete pompöse Wesen an den Tag, das Bewohnern der iberischen Halbinsel in der zeitgenössischen ethnographischen Literatur unterstellt wurde. Dass er wenig später den anderen europäischen Kavalieren vorschlägt, die mittlerweile volltrunkene deutsche Dame im „Schlaffe [zu] erwürgen, ${ }^{377}$ beweist seine Grausamkeit; der Ausruf „Per Dio santo ${ }^{638}$ wiederum erinnert an die den Spaniern nachgesagte bigotte Frömmigkeit. Wie auch die anderen allegorischen Figurationen europäischer Mächte verkörpert Don Antonio demnach all jene Stereotypen, welche im zeitgenössischen Diskurs über Nationalcharaktere mit bisweilen ermüdender Insistenz wiederholt wurden.

Erhellender noch als die vorgängig zitierten Stellen aus Johann Rists Bühnendichtungen ist mit Blick auf die hier interessierende Fragestellung ein Werk des Wedeler Pastors, das in der germanistischen Forschung fast völlig übergangen wurde: Es handelt sich um einen gereimten Text, der erstmals 1635 in den Druck gelangte und 1636 sowie 1640 unter dem Titel Capitan Spavento Oder Rodomontades espagnolles. Das ist: Spanische Auffschneidereyen/ auß dem Frantzösischen in deutsche Verß gebracht noch

33 Johann Rist: Sämtliche Werke. Hrsg. von Eberhard Mannack (unter Mitwirkung von Helga Mannack). Bd. 1: Dramatische Dichtungen (Irenaromachia. Perseus). Berlin 1967, S. 71. (=Ausgaben deutscher Literatur des XV. bis XVIII. Jahrhunderts)

34 Johann Rist: Sämtliche Werke. Hrsg. von Eberhard Mannack (unter Mitwirkung von Helga Mannack und Klaus Reichelt). Bd. 2: Dramatische Dichtungen (Das Friedewünschende Teutschland. Das Friedejauchtzende Teutschland). Berlin 1972, S. 86. (=Ausgaben deutscher Literatur des XV. bis XVIII. Jahrhunderts)

35 Ebenda, S. 94.

36 Ebenda, S. 90.

37 Ebenda, S. 102.

38 Ebenda, S. 104. 
einmal veröffentlicht wurde. Wie der Titel verrät, handelt es sich um die Übersetzung einer französischen Vorlage, die die Forschung als die Rodomontades Espagnoles des Jesuiten und Rektors des Kollegiums von Grenoble, Jacques Gaultier, identifiziert hat. ${ }^{39}$ Gaultiers Werk wiederum weist eine große Nähe zu Francesco Andreinis erstmal 1607 veröffentlichten Bravure del Capitano Spavento auf, einem Kompendium all jener hyperbolischen Formulierungen, mit denen der prahlerische ,Capitano" der Commedia dell'arte seine soldatischen Verdienste zu preisen pflegt. ${ }^{40}$ Obwohl es sich bei Rists Capitan Spavento demnach nicht um eine eigenständige Schöpfung handelt, eine Schöpfung die überdies die literarische Tradition, in der sie steht, an keiner Stelle verleugnet, ist der Text nicht frei von allerdings nicht um Aktualität bemühte Andeutungen auf geschichtliche Erfahrung. So wird in der Suada des Hauptmanns, in der dieser mittels immer kühnerer Hyperbeln seine militärischen Heldentaten beschwört, auf die Belagerung Ostendes durch ein spanisches Heer hingewiesen ${ }^{41}$ und an anderer Stelle der umfassende Herrschaftsbereich der Habsburger explizit benannt. ${ }^{42}$ Auch ein Satz wie ,der Spanier ists/ Ach weh der wird uns morden Nun lauff wer lauffen kann" ${ }^{\text {c43 }}$ darf als Reminiszenz an die in der antispanischen Publizistik des späten 16. und frühen 17. Jahrhunderts immer wieder betonte Grausamkeit der spanischen Soldaten gelesen werden, und wenn sich Capitan Spavento in Strophe 51 als unbesiegbarer Seefahrer rühmt, erscheint dies vor dem Hintergrund des Untergangs der spanischen Armada 1588 als ironische Spitze, welche den Lesem nicht verborgen geblieben sein dürfte. Ungeachtet der hier benannten historischen Allusionen kann kein Zweifel daran bestehen, dass es dem Autor in erster Linie um die rhetorisch souveräne Gestal-

39 Vgl. Fausto de Michele: Der "Capitano" der Commedia dell" arte und seine Rezeption und Entwicklung im deutschsprachigen Theater. In: Daphnis 31 (2002), S. 529-591, hier S. 545.

40 Auf eine zeitgenössische deutsche Übersetzung von Andreinis Le Bravure del Capitan Spavento hat Alberto Martino aufmerksam gemacht: Die italienische Vorlage des „Hauptmann Schreck“ (1627). In: Wolfenbütteler Barocknachrichten 22 (1995), S. 102-107.

41 Vgl. Johannis Ristii Holsati Capitan Spavento Oder Rodomontades Espagnolles. Das ist: Spanische Auffschneidereyen/ auB dem Frantzösischen in deutsche Verß gebracht. Zum Drittenmahl Gedruckt bey Johann Gurtwasser/ in Verlegung Tobia Gundermans/ Buchführer/ 1640, Strophe XLII., wo es heiBt: „Als ich mit grosser macht bin vor Ostend gelegen“". Die Belagerung Ostendes durch spanische Truppen fallt in die Jahre 1601-1603.

42 Vgl. ebenda, Strophe XXVI., wo Capitan Spavento auf die Säulen des Herkules und damit auf Gibraltar als äuBersten Rand des europäischen Machtbereichs der Habsburger und zugleich auf deren Territorien jenseits des Atlantiks hinweist.

43 Ebenda, Strophe XXXIX. 
tung eines Repräsentanten der italienischen Stegreifkomödie geht. Im Rückgriff auf den in der europäischen Theaterliteratur beliebten Typus des gleichermaßen in militärische und erotische Abenteuer verstrickten miles gloriosus bietet er seinen Lesern die für die Figur des bramarbasierenden Soldaten übliche Aneinanderreihung hyperbolischer Beschreibungen militärischer Bravourstücke. ${ }^{44}$ Nicht zufällig stellt Rist sich in seinem Proömium denn auch in eine Reihe mit jenen "Comœdien vnd Tragœdien" des Plautus, des Terenz, aber auch italienischer, französischer und deutscher Dramatiker, in denen alte Geizhälse, junge Buhler, diebische Knechte oder eben „auffschneiderische[n] Soldaten vnd Leimstengeler" die zentrale Rolle spielen. ${ }^{45}$ Sein Werk, das er dem in dänischen Diensten tätigen Offizier Johann Petersen widmet, einem „Capitain“, der, wie Rist hervorhebt, anders als sein literarisches Gegenstück ,nicht allein den Kriegerischen Mars/ besondern auch den Gelahrten vnnd Kunstreichen Apollo jhme lesset lieb/ angenehm vnd befohlen seyn" ${ }^{46}$ versteht sich, wie die Vorrede deutlich macht, vor allem als poetische Fingerübung in der Nachfolge Martin Opitz'; sie dokumentiert weniger Rists politische Überzeugungen als vielmehr dessen poetische Ambitionen und orientiert sich dabei an vom Autor kenntlich gemachten literarischen Mustern. Dies hindert Rist allerdings nicht daran, im selben Kontext die Aufgabe der Dichtung auch darin zu erkennen,

die fehler vnd gebrechen vnterschiedlicher Nationen vnnd Völcker [...] fein bescheidenlich zu straffen vnd zu tadelen/ inmassen dann heut zu Tage so wohl vnter den Teutschen/ als Jtaliäneren/ Spaniern vnd Frantzosen viel treffliche Leute gefunden werden/ die so wol jhrer eigenen Landsleute als anderer außländischen Nationen Mängel vnd Gebrechen so zierlich vnd bescheidenlich zu corrigiren wissen. ${ }^{47}$

Jenseits literarischer Typik werden hier nationale Stereotypen als adäquate Beschreibungsmodi kultureller Eigenart postuliert und der Capitan Spavento folgerichtig als eine Figur verstanden, die ,nicht allein sein eigenes auffgeblasenes Gemüth verrathen/ besondern was von seinen Landesleuten zu

44 Dass sich Johann Rist bei der Gestaltung seines Capitan Spavento vom literarischen Typus des miles gloriosus inspirieren lieB, betont auch Gerhart Hoffmeister: Versuch einer Typologie des „spanischen Narren“ zwischen 1613 und 1787. In: Literary Culture in the Holy Roman Empire 1555-1720. Hrsg. von James Parente, Richard Erich Schade und George C. Schoolfield. Chapel Hill und London 1991, S. 89-105, hier S. 94.

45 Ebenda, Aiij.

46 Ebenda, $A v^{\prime}-A v^{2}$.

47 Ebenda, Aij". 
halten/ aller Welt hat zuerkennen gegeben. ${ }^{\text {c4s }}$ Es erscheint so gesehen nur konsequent, wenn der Autor sein Werk mit dem Wunsch beendet, „der Maran“ möge verstehen, „Das er hiemit gemeint" sei, und auf diese Weise noch einmal den Zusammenhang zwischen poetischer Imagination und historischer Wirklichkeit herausstellt. ${ }^{49}$

Johann Rists Capitan Spavento erweist sich bei näherer Betrachtung als merkwürdig ambivalent: Indem Rist Bezüge zu geschichtlicher Erfahrung zumindest andeutet und seinen Protagonisten in der Vorrede als repräsentativ für ,den' Spanier überhaupt einführt, behauptet er einen Realitätsgehalt seiner Dichtung, den er an anderer Stelle relativiert. Wer, wie dies Christoph Eugen Schweitzer in seiner Dissertation über die Darstellung Spaniens in der deutschen Literatur des 17. Jahrhunderts getan hat, nur die Übereinstimmungen mit dem zeitgenössisch verbreiteten negativen Stereotyp , des' Spaniers in den Blick nimmt und Rist einer dezidiert antispanischen Haltung bezichtigt, ${ }^{50}$ übersieht demnach Entscheidendes: Zwar ist davon auszugehen, dass Rist als protestantischer Parteigänger wenig Sympathie für die spanische Politik gehegt haben dürfte und das verbreitete Stereotyp ,des' Spaniers seiner ablehnenden Haltung gegenüber den Angehörigen einer Kriegsmacht, die in der zeitgenössischen Publizistik immer wieder für das Leiden der evangelischen Bevölkerung im Reich verantwortlich gemacht wurde, entgegenkam, dennoch geht es Rist nicht in erster Linie um die Denunziation Spaniens und der Spanier. Die primäre Absicht seines Werks besteht vielmehr darin, sich als Poet zu präsentieren, welcher die Regeln der sich modernisierenden deutschen Kunstdichtung vollkommen beherrscht. ${ }^{51}$ Was nun könnte dafür geeigneter sein als die Rodomontaden eines prahlerischen Soldaten, in denen nicht die Darstellung komplexer Handlungsstränge, sondern die Sprache mit ihrem Reichtum an Bezeichnungen für das Immergleiche im Zentrum steht? Die Demonstration literarischer Kompetenz erschöpft sich allerdings nicht in der Fülle rhetorischer Mittel, deren der Autor sich in seiner Gestaltung des spanischen Capitano bedient. Der auch in Rists Dramen offenkundige und sich dort keinesfalls nur auf spanische Protagonisten beschränkende Rekurs auf die Diskussion über die europäischen Nationalcharaktere, der den Wedeler Geistlichen als gelehrten Autor erweist, die Originalität der sprachlichen Metaphern, mit welchen der Dichter sein poetisches

48 Ebenda, Aiij火.

49 Ebenda, Beschluß.

50 Vgl. Schweitzer, Spanien in der deutschen Literatur (wie Anm. 29), S. 56f.

51 Ähnliches hat Albert Martino mit Blick auf den von ihm vorgestellten pseudonym erschienenen Hauptmann Schreck, den er im Umfeld der Fruchtbringenden Gesellschaft verortet, herausgestellt. Vgl. Martino, „Hauptmann Schreck“ (wie Anm. 40), S. 105. 
ingenium unter Beweis stellt, ${ }^{52}$ die Wahl des Alexandriners, die besonders augenfällig das Spannungsfeld von Imitation und autonomer Imagination, in dem Rist sich als literarischer Übersetzer bewegt, vor Augen führt, die rhetorische Brillanz eines Selbstlobs, das, in dem Maße, in dem es den Protagonisten der Lächerlichkeit preisgibt zugleich die poetische Begabung seines Urhebers ins Blickfeld ruickt - all dies dient dazu, die Einbildungskraft und das Sprachvermögen Rists herauszustellen, der hier nicht nur als Übersetzer, sondern zugleich als Verfechter eines neuen Dichtungsideals agiert, dem er bereits in seiner ein Jahr zuvor veröffentlichten Musa Teutonica gehuldigt hatte. ${ }^{53}$ Wenn zutrifft, dass Stereotypen eine starke Affinität zu spezifischen Formen rhetorischen Ausdrucks, insbesondere zur Hyperbel, zur Metapher, zur Synekdoche sowie zur Allegorie, eignet, ${ }^{54}$ wird verständlich, weshalb gerade der auf den ersten Blick nur bedingt attraktive Typus der literarischen Rodomontade für Rist eine reizvolle Herausforderung bot. Sie stellt jenen reichhaltigen Fundus an poetischen Beschreibungsmustern zur Verfügung, die Rist für seinen parallel zum Capitan Spavento entstandenen Perseus, dessen Hauptfigur ebenfalls Züge eines miles gloriosus trägt, nutzen konnte, und erlaubt es dem sich als Dichter verstehenden Übersetzer zugleich, im Rahmen einer tendenziell freien Adaption sein poetisches Talent in hellstem Licht erstrahlen zu lassen.

\section{III.}

Zweifellos ist die deutschsprachige Literatur der ersten Hälfte des 17. Jahrhunderts nicht unberührt geblieben von einer sich in unterschiedlichen Medien artikulierenden stereotypen Konzeptionalisierung der iberischen Halbinsel und ihrer Bewohner. Auch in Rists Werk finden sich Belege für die wirkungsgeschichtliche Relevanz jenes literarisch und publizistisch vermittelten Topos des stolzen und grausamen Spaniers, der den Kern der ,leyenda

52 Die in der Vorrede zunächst auf den Verfasser der französischen Vorlage gemünzte Formulierung des ,feinen/ lustigen/ Poetischen Ingenio“ (Aiij”) druickt zugleich den Anspruch aus, den Rist an sich selber stellt.

53 Zu Johann Rists Musa Teutonica und deren Bedeutung für die Vermittlung der Opitzschen Versreform in Norddeutschland vgl. Ulrich Moerke: Die Anfänge der weltlichen Barocklyrik in Schleswig-Holstein. Hudemann - Rist - Lund. Mit einem Textanhang: Briefe und Gedichte von Heinrich Hudemann, Johann Rist und Zacharias Lund. Neumünster 1972, S. 88-132.

54 Vgl. Angelika Plum: Die Karikatur im Spannungsfeld von Kunstgeschichte und Politikwissenschaft. Eine ikonologische Untersuchung zu Feindbildern in Karikaturen. Aachen 1998, S. 81-104. 
negra' ausmacht. Wenn allerdings die Darstellung ,des ' Spaniers sogar bei einem derart politischen Autor wie Rist innerhalb des Gesamtwerks von eher marginaler Bedeutung bleibt und sich außerdem, wie ich zu zeigen versuchte, vorrangig literarischen Intentionen verdankt, wirft dies noch einmal die Frage nach der Relevanz nationaler Stereotype in barocker Dichtung auf: Ungeachtet der Tatsache, dass die in gelehrtem Schriftum vermittelten Vorstellungen hinsichtlich der Eigenart ,des' Spaniers den sich als poetae docti verstehenden Autoren des 17. Jahrhunderts nicht unbekannt waren, erweist sich die literarische Behandlung Spaniens und der Spanier in der deutschsprachigen Literatur der Fruihen Neuzeit als bemerkenswert inkonsistent. ,Der' Spanier tritt einerseits mit jenen Attributen behaftet auf, die ihm den zeitgenössischen ethnologischen Vorstellungen gemäß zugeordnet werden konnten, und gehorcht andererseits spezifisch literarischen Intentionen, die, so der Befund, dessen konkrete Ausgestaltung in der Regel in höherem MaBe beeinflussten als diskursiv erzeugte stereotype Setzungen. Dies dürfte nicht allein damit zusammenhängen, dass der poetische Text im hier untersuchten Fall stärker dem Einfluss innerliterarischer Regeln als demjenigen außerliterarischer Normen ausgesetzt war, sondern auch damit, dass die Wahrnehmung Spaniens in Europa sowohl durch die im antispanischen Diskurs vermittelten Feindbilder geprägt war, als auch durch die Erfahrung des Aufstiegs Spaniens zur Weltmacht. Im Moment seiner größten Ausdehnung unter Philipp II. umfasste das iberische Königreich weite Gebiete Europas sowie riesige Territorien jenseits des Atlantiks und so verwundert es kaum, dass Spanien bis gegen die Mitte des 17. Jahrhunderts in politischmilitärischer und in kultureller Hinsicht auf dem europäischen Kontinent eine Vormachtstellung einnahm. Dieser Vormachtstellung verdankt sich unter anderem die Wirkung spanischer Autoren und Werke auf die deutsche Literatur des Barock, eine Wirkung, welche die Perzeption der spanischen Kultur nicht weniger determiniert haben dürtte als die tendenziell skeptische Einschätzung Spaniens in chronikalisch-ethnographischen, enzyklopädischen und politisch-publizistischen Darstellungen.

Die engen kulturellen und insbesondere literarischen Beziehungen zwischen Spanien und dem Heiligen Römischen Reich Deutscher Nation, die hier nur angedeutet werden sollen, bilden seit längerem einen Gegenstand germanistischer und hispanistischer Forschungsbemühungen." Der Einfluss im Lichte der deutschen Kritik und Poesie. In: Zeitschrift für Vergleichende Literaturgeschichte N. F. 5 (1892), S. 135-206 und S. 276-332 sowie Zeitschrift für Vergleichende Literaturgeschichte N. F. 8 (1895), S. 318-370 und Hermann Tiemann: Das Spanische Schrifttum in Deutschland von der Renaissance bis zur Romantik. Eine Vortragsreihe. Hamburg 1936 (Reprint Hildesheim und New 
Spaniens auf die deutschsprachige Dichtung, der uns hier vor allem interessieren soll, manifestiert sich zunächst im Gattungsgefüge, das erheblich von Entwicklungen profitiert, deren Ursprünge auf die Literatur der iberischen Halbinsel zurückgehen. So kommt spanischen Vorbildern etwa im Bereich des Ritter- und des Schäferromans große Bedeutung zu: Seit dem 16. Jahrhundert häufen sich die deutschsprachigen Übersetzungen spanischer Romane; die früh einsetzende Kontroverse um den Amadís de Gaula, der seit 1569 zunächst in Teilen - in deutscher Sprache zugänglich ist, rückt außerdem ein besonders populäres und in seiner Wirkung auch auf die Literatur des 17. Jahrhunderts nur schwer zu überschätzendes Beispiel höfischer Prosa ins Blickfeld. 1619 erscheint in Nümberg außerdem eine deutsche Übertragung von Jorge de Mayors Diana mit der Fortsetzung von Gil Polo und bestätigt die überragende Bedeutung Spaniens für den europäischen Barockroman. Stärker noch als der Einfluss des höfischen war allerdings der Einfluss des pikaresken Romans, für den Spanien die grundlegenden Modelle lieferte. Der 1554 anonym gedruckte Lazarillo de Tormes wurde 1614 erstmals ins Deutsche übertragen und 1617 in Augsburg gedruckt, ${ }^{56} 1615$ lag Aegidius Albertinus Bearbeitung von Mateo Alemáns 1599 veröffentlichtem Guzmán de Alfarache vor, ${ }^{57} 1648$ erschien schließlich die erste deutsche Teilfassung von Miguel de Cervantes' Don Quijote (1605/1615) im Druck. Weniger offenkundig als derjenige des Schelmenromans, dem die deutsche Literatur ihre vielleicht bedeutendste Prosadichtung, Hans Jakob Christoffel von Grimmelshausens Abenteuerlicher Simplicissimus Teutsch, verdankt, ist der Einfluss des spanischen Dramas - hier wären vor allem Félix Lope de Vega und Pedro Calderón de la Barca zu nennen - und derjenige der Novellistik und der weltlichen sowie der geistlichen Lyrik, der sich insbesondere im Bereich der mystischen Dichtung manifestiert.

Eine intensive Rezeption hat in Deutschland neben den vorgängig genannten poetischen Artefakten auch die spanische Moralphilosophie erfahren. So wurden etwa Antonio de Guevaras Werke Reloj de príncipes (1529) und Menosprecio de corte y alabanza de aldea (1539) oder seine Epístolas familiares (1539-41) von Aegidius Albertinus bearbeitet, Diego Saavedra Fajardos Fürstenspiegel mit dem Titel Idea de un príncipe político-cristiano (1640) fand auch in Deutschland ein bemerkenswertes Echo und Baltasar Graciáns Schriften Oraculo manual (1647), Agudeza y arte de ingenio

York 1971) sowie Schweitzer, Spanien in der deutschen Literatur (wie Anm. 29) und v. a. Gerhart Hoffmeister: Spanien und Deutschland. Geschichte und Dokumentation der literarischen Beziehungen. Berlin 1976. (=Grundlagen der Romanistik 9)

56 Vgl. Hoffmeister, Spanien und Deutschland (wie Anm. 55 ), S. 74.

57 Vgl. ebenda, S. 74f. 
(1648) oder Criticón (1651-1657) haben noch bis weit in die Frühaufklärung hinein ihre Wirkung entfaltet. Wenn Johann Rist in Das Friedejauchtzende Teutschland Zwischenspiele nach dem Vorbild des Don Quijote integrier ${ }^{58}$, wenn Johann Michael Moscherosch seine Wunderlichen und Wahrhafftigen Gesichte Philanders von Sittewalt nach dem Muster der Sueños y discursos de verdades (1627) des Francisco de Quevedo y Villegas gestaltet, wenn Georg Philipp Harsdörffer sich in vielfältiger Art und Weise von spanischen Autoren inspirieren lässt ${ }^{59}$ bestätigt dies das Interesse, das deutsche Autoren der ersten Hälfte des 17. Jahrhunderts der spanischen Literatur entgegenbrachten.

Die Wahmehmung Spaniens als eines politischen und kulturellen Raumes gestaltet sich innerhalb der deutschsprachigen Literatur demnach weitaus komplexer und insgesamt positiver als dies jene Autoren, die einen engen Zusammenhang zwischen dem sich in der ,leyenda negra' verdichtenden antispanischen Diskurs und der Behandlung Spaniens in der Dichtung erkannt haben wollen, postulieren. ${ }^{\infty} \mathrm{Zwar}$ ist, wie bereits betont, den zumeist protestantischen barocken Autoren die problematische Rolle, die Spanien in politischer Hinsicht spielte, durchaus bewusst gewesen; das hinderte sie allerdings nicht daran, erstens ohne Bedenken aus dem reichhaltigen Fundus der spanischen Literatur zu schöpfen und zweitens bei der Gestaltung spanischer Protagonisten nicht wesentlich schematischer zu verfahren, als sie dies bei der Darstellung italienischer, französischer oder englischer Akteure taten. ${ }^{61}$ Anschaulich führt dies gerade der hier besonders interessierende Typus

58 Vgl. Ingrid Schiewek: Theater zwischen Traditionen und Neubeginn. Die Zwischenspiele des Johann Rist. In: [Autorenkollektiv:] Studien zur deutschen Literatur im 17. Jahrhundert. Berlin und Weimar 1984, S. 145-251, hier S. 245.

59 Zum Einfluss der spanischen Literatur auf Harsdörffers Werk vgl. Schweitzer: Spanien in der deutschen Literatur (wie Anm. 29), S. 171-213.

60 Besonders nachdrücklich hat Christoph Eugen Schweitzer einen engen Zusammenhang zwischen antispanischem Schrifttum und der Darstellung des Spaniers in der deutschen Dichtung behauptet. „Es ist jedoch wesentlich“ - so seine These - ,die deutschen Schriften dieser Zeit auf ihre Haltung gegenüber den politischen Zielen Spaniens und der physischen Gegenwart seiner Heere in Deutschland zu untersuchen. Sie bildet einen Ausgangspunkt für die Beurteilung Spaniens und seiner Bewohner seitens Deutschland und stellt damit einen wichtigen Bestandteil der Darstellung von Spaniem in der deutschen Literatur dar." [Schweitzer, Spanien in der deutschen Literatur (wie Anm. 29), S. 19]. Auch Fausto de Michele sieht einen Zusammenhang zwischen der biographischen Erfahrung Johann Rists und dessen Gestaltung spanischer Soldaten nicht nur in Capitan Spavento [De Michele, Der ,.Capitano“ der Commedia dell"ane (wie Anm. 39), S. 541].

$61 \mathrm{Vgl}$. Das Friedewünschenden Teutschland. in dem ein mit ,einem Spanischen Wamse/ Französischen Hosen/ Polnischen oder Krabatischen Mützen“" bekleide- 
des miles gloriosus vor Augen, der in seiner neuzeitlichen Form als Figur der Commedia dell'arte zwar italienischer Herkunft ist, jedoch im 16. Jahrhundert meist französische und spanische Soldaten verkörpert, nach 1600 vor allem als spanischer "Capitan" in Erscheinung tritt, um schließlich zunehmend international und polyglott zu agieren - etwa in Andreas Gryphius' Horribilicribrifax -, ohne dass sein Rollenprofil deshalb signifikante Änderungen erführe. Dieses eigentümliche Schwanken der nationalen Zuschreibungen, die in einer Reihe fiktionaler Werke zu beobachtende Austauschbarkeit bzw. Überlagerung nationaler Stereotypen stützt die Vermutung, dass es den Autoren weniger darum ging, ein überliefertes Inventar nationaler Eigenschaftszuweisungen in politischer Absicht zu nutzen, sondern vielmehr darum, die Interaktion zwischen den von ihnen entworfenen Figuren den poetischen Absichten gemäß, die sie mit deren Darstellung verbanden, zu gestalten. Dort, wo nationale Stereotypen diesen poetischen Absichten dienten, kamen sie zur Anwendung; dort, wo sie ihnen entgegenstanden, wurden sie ignoriert oder modifiziert. Beispielhaft lässt sich dies etwa in Johann Rists Das Friedejauchtzende Teutschland verdeutlichen, wo Jberus, die allegorische Personifikation des spanischen Königreichs, sich in Bescheidenheit und Friedfertigkeit übt und damit dem Charakter einer Bühnendichtung Rechnung trägt, die den endlich zustande gekommenen Frieden von Münster und Osnabrück feiert. ${ }^{6 ?}$

Wenn nun allerdings nationalen Stereotypen in fiktionalen Texten nicht jene Bedeutung zukommt, die angesichts der Ubiquität antispanischer Topoi in der ersten Hälfte des 17. Jahrhunderts zu erwarten wäre, stellt sich die Frage, weshalb sie überhaupt in die barocke Dichtung Eingang gefunden haben. Deren Verwendung, so meine These, lässt sich nicht vorrangig mit der politischen Haltung deutschsprachiger Autoren begründen, ebenso wenig verdankt sie sich allein dem Bestreben, bei der Darstellung spanischer Figu-

ter Sänger die Bühne betritt, um „mit einem hönischen und offtverenderten Gesichte/ bald als ein ernsthaffter Spanier/ bald als ein leichtsinniger Franzose/ bald als ein schmeichelhaffter Italianer" ein Lied zum Besten zu geben, das den verderblichen Einfluss fremder Mächte in Deutschland thematisiert [Rist, Sämtliche Werke. Bd. 2 (wie Anm. 34), S. 104f.].

62 Vgl. etwa Jberus' Ansprache an Teutschland im zweiten Akt, in der er betont: „Jch bin nicht zu dem Ende auff dieses mahl anhero kommen/ daB ich mit sonderem Prachte von Teutschland wolte empfangen werden/ vielmehr habe ich einer solchen großmächtigen Königin/ welcher der unersättlicher [!] Mars mit nicht weniger Grausamkeit/als mir und ihrer Tochter Batavien schon viele Jahre hat zugesetzet/ zur sonderbaren Lust und Ergötzlichkeit wollen zeigen/ welcher gestalt ich mit mehrgedachter Prinzessin Batavien nunmehr in gar guter und Nachbarlicher Vertrauligkeit lebe.“ [Rist, Sämtliche Werke. Bd. 2 (wie Anm. 34), S. 360]. 
ren dem nicht nur von Hippolyte-Jules Pilet de la Mesnardière formulierten Postulat einer dem Gesetz der Wahrscheinlichkeit verpflichteten Literatur zu genügen; entscheidender als die genannten Motive ist die Tatsache, dass Stereotype in besonderem Maße geeignet sind, spezifischen Bedürfnissen poetischer Konfiguration zu genügen. Literarische Aussageweisen, etwa jene, die für komische Genres als konstitutiv gelten, sind wesentlich durch ihre Affinität zu Prozessen der Stereotypisierung gekennzeichnet. ${ }^{63}$ Strategien der Kontrastbildung, Modi der Differenzierung zwischen Figuren unterschiedlicher Relevanz - etwa zwischen vergleichsweise subtil ausgearbeiteten Haupt- und typenhaft überzeichneten Nebenfiguren - oder die vom Autor bewusst intendierte und für den Leser bzw. Zuschauer transparente Orientierung an Iiterarischen Prototypen begünstigen die Ausbildung literarischer Stereotype, die denn auch seit der Antike ein wichtiges Instrument poetischer Formgebung bilden. Wenn es demzufolge in erster Linie die Konventionen einer Gattung wie zum Beispiel der Typenkomödie, des allegorischen Spiels mit seiner Tendenz zur Abstrahierung, der Satire oder des pikaresken Romans, wenn es die Autorität poetologischer Präskriptionen sowie der Einfluss literarischer Vorbilder sind, die über die Art und Weise, wie Stereotype in literarischen Texten Verwendung finden. entscheiden, bedeutet dies, dass nationale Stereotype in literarischen Werken auch dort, wo sie nicht von den in der gelehrten Diskussion um Nationalcharaktere vermittelten Eigenschaftszuweisungen zu unterscheiden sind, einer eigenen, den Regeln ästhetischer Kommunikation verpflichteten Logik unterliegen.

So plausibel die These eines primär instrumentellen Charakters nationaler Stereotype in poetischen Texten mit Blick auf dichterische Hervorbringung sein dürfte, so fragwürdig erscheint sie mit Blick auf literarische Konsumption. Es ist davon auszugehen, dass zumindest die protestantischen Rezipienten jener Werke, in denen Spanien und ,der' Spanier eine Rolle spielen, Zusammenhänge zwischen ästhetisch zu begrïndenden Darstellungsmustern und lebensweltlicher Erfahrung zu erkennen bemüht waren. Was auf der Produktionsebene als literarischer Topos funktionierte, hat, so steht zu vermuten, auf der Rezeptionsebene jene Wirkungen entfaltet, welche die sozialpsychologische Forschung mit Stereotypen in Verbindung bringt. Als affektiv aufgeladene und moralische Werturteile integrierende Setzungen begünstigen Stereotype eine emotionale und ethisch intransigente Wahrnehmung und so dürften die Reaktionen der Leser bzw. Zuschauer nicht allein durch deren literarischen Erwartungs-, sondern zugleich und vor allem durch deren kulturellen Erfahrungshorizont geprägt gewesen sein.

63 Vgl. hierzu z. B. Günther Blaicher: Einleitung des Herausgebers: Bedingungen literarischer Stereotypisierung. In: Blaicher (Hg.), Erstarrtes Denken (wie Anm. 21), S. 9-25. 
Es gehört zu den Vorteilen des mittlerweile ubiquitären Begriffs ,Diskurs', dass er es ermöglicht, Vorstellungen, die in unterschiedlichen Medien artikuliert wurden, als Zusammenhang zu beschreiben. Allzu leicht gerät dabei allerdings in Vergessenheit, dass Medien bzw. zusammengehörige Ensembles von Medien auch dann eigenen Gesetzmäßigkeiten folgen, wenn sie Teil einer übergeordneten diskursiven Formation sind. Die Darstellung ,des' Spaniers in der deutschsprachigen barocken Literatur bewegt sich in dem hier angedeuteten Spannungsfeld: Vor dem Hintergrund eines zunehmend dynamischen publizistischen Marktes und der daraus resultierenden Kommunikationsverdichtung, welche die Voraussetzungen für die Popularisierung nationaler Stereotypen schuf, blieb auch die fiktionale Literatur nicht unberührt von den in der, leyenda negra' konvergierenden antispanischen Auffassungen. Wie am Beispiel einiger Dichtungen Johann Rists gezeigt werden konnte, fanden jene Topoi, welche den Diskurs über Spanien und ,den' Spanier dominierten, auch in die fiktionale Literatur Eingang und trugen dazu bei, das Bild des Spaniers zu modellieren. Zugleich jedoch dürfte deutlich geworden sein, dass Dichtung in Bezug auf den Umgang mit nationalen Stereotypen ein zumindest partiell autonomes System bildet. Auch wenn davon auszugehen ist, dass die Rezipienten auf nationale Stereotypen in literarischen Artefakten nicht unbefangen reagierten, sondern die in ihrem Wissenshorizont verankerte, individuell und kollektiv geprägte Imagination des Spaniers in ihre Wahrnehmung eines dichterischen Textes oder eines Bühnenstücks integrierten, gilt, dass das Kommunikationssystem ,Literatur' mit den ihm inhärenten Normen poetischer Konfiguration für die Gestaltung nationaler Charaktere und die von diesen ausgehenden Wirkungen wichtiger war als der in zahlreichen Medien reproduzierte Topos des stolzen und grausamen Spaniers. Das heißt nicht, dass die von der komparatistischen Imagologie verfochtene These eines engen Zusammenhangs zwischen gesellschaftlich vermittelten Vorstellungen und dichterischer Imagination obsolet wäre. Die Dichtung des 17. Jahrhunderts bildet keinen völlig eigenständigen, von lebensweltlichen Erfahrungen und historischen Entwicklungen abgekoppelten Bereich, sondem bedient sich ihres zeitgenössischen, outillage mental " und greift damit auch auf vorherrschende Auffassungen nationaler Eigenart zurück; im Prozess der Literarisierung werden ebendiese Auffassungen nationaler Eigenart allerdings konsequent den Gesetzen poetischer Darstellung unterworfen und damit in eine ästhetische Aussageform überfuihrt, die deren gesellschaftliche Bedeutung auf entscheidende Weise modifiziert. 